\title{
Directed Forgetting, Event-Related Potentials and Nicotine
}

\author{
MAGNUS LINDGREN ${ }^{1,2 *}$, GEORG STENBERG ${ }^{1}$ and INGMAR ROSÉN ${ }^{2}$ \\ ${ }^{1}$ Department of Psychology, Lund University, 22185 Lund, Sweden \\ ${ }^{2}$ Division of Clinical Neurophysiology, Department of Clinical Neuroscience, Lund University, \\ University Hospital, 22185 Lund, Sweden
}

Fifteen male users of oral snuff performed a directed forgetting task after over-night abstinence and after administration of oral snuff. Directed forgetting tasks use cues to classify items for differential reporting at test, emphasizing the need for strategic encoding. Recognition was better after nicotine administration, but we found no evidence for greater strategic control, as hypothetically reflected in successful compliance with the directed forgetting instruction. Reaction time decreased after nicotine administration. Performance among 15 controls was unaffected over two sessions. Copyright (C) 1999 John Wiley \& Sons, Ltd.

KEY WORDS - nicotine; oral snuff; memory; ERPs; reaction time

\section{INTRODUCTION}

Studies of nicotine effects on cognitive functions in man are remarkably variable in results and interpretation (Heishman et al., 1994). Memory effects have been one of the central issues. Animal studies show a fairly consistent picture of modest working memory improvement (Levin, 1992), for instance a decrease in radial maze errors after chronic nicotine administration to rats (Levin et al., 1996). Human studies of long-term memory performance after pre-trial nicotine administration have, however, been less conclusive (Heishman et al., 1994). Studies have, over varying retention delays, shown improvement (Peeke and Peeke, 1984; Warburton et al., 1992a,b; Rusted et al., 1995 [Exp.4]), no change (Parrott and Winder, 1989; Foulds et al., 1996), or impairment (Houston et al., 1978; Spilich et al., 1992). When improvement has been found, it has usually been modest (Heishman et al., 1994).

In the study by Warburton et al. (1992b), the results indicated that nicotine emphasized performance patterns found in abstinence; subjects with strong primacy effects enhanced that effect after nicotine administration, with the corresponding

\footnotetext{
*Correspondence to: M. Lindgren, Division of Clinical Neurophysiology, Department of Clinical Neuroscience, University Hospital, 22185 Lund, Sweden. Fax: +46 4614 6528. e-mail: Magnus.Lindgren@psykol.lu.se

result for recency effects. In discussing these findings Warburton et al. suggested that the performance improvements reflect a strategic deployment of resources, facilitated by nicotine, an idea that seems closely related to the concept of nicotine as a cognitive enhancer (Warburton, 1992). However, if this pattern is not merely due to an accentuated, but stable, personal performance characteristic, nicotine administration should facilitate the compliance with encoding manipulations, such as directed forgetting (see, for example, Paller, 1990; Johnson, 1994). Directed forgetting experiments employ an encoding cue, e.g. colour, to designate test items into one group to be remembered and reported as old at test (R-words), and one to be forgotten and reported as new (F-words). At the test stage, this procedure can be regarded as an exclusion task (see, for example, Jacoby et al., 1993) within a standard recognition task (see Wilding and Rugg, 1997, for a similar design in a non-pharmacological context). The exclusion paradigm demands that certain old items be reported as new. One might then apply a dual-process conceptualization of recognition (Jacoby, 1991), where both familiarity (a sense of having encountered the item recently) and recollection (a retrieval of context, pinpointing the item in time) will play a part. The estimation of these components is currently under vigorous debate (Mulligan and Hirshman, 1997; Curran and Hintzman, 1997; Jacoby et al., 1997), but for the present 
study, it is sufficient to note that the correct classification of an old word in a directed forgetting task cannot solely rely on familiarity, as recollection of context information is necessary to decide whether the word belongs to the R- or F-class. New words, on the other hand, can be classified on the basis of less familiarity. Hence, one might assume that strategic resource deployment in this task would comprise a more elaborate encoding, taking advantage of whatever contextual information the subject can generate to facilitate classification at test.

The analysis of the recognition data in this experiment is based on two signal detection measures: $\mathrm{d}_{\text {new }}$, calculated from R-words and new words, and $\mathrm{d}^{\prime}{ }_{\text {old }}$, encompassing the $\mathrm{R}$ - and F-words. The critical test of strategic resource deployment is then arguably an increase of $\mathrm{d}^{\prime}$ old after nicotine administration, as this would call for more extensive context retrieval, whereas $\mathrm{d}^{\prime}{ }_{\text {new }}$ reflects recognition without any more precise classification.

Given that a differential encoding takes place, event-related potentials might elucidate the encoding process. A classic ERP signature in a colourguided selection task is the frontal P205, a positive deflection in the response to items of the target colour (Hillyard and Münte, 1984; Wijers et al., 1989). However, in this study all items required further processing and it is therefore likely that the P205 effect would be attenuated. Instead, one might hypothesize that the R-words should be accompanied by an increased late positivity, akin to the Dm effect described by Karis et al. (1984), as an indication of more elaborate encoding.

The ERP repetition effect, that previously encountered stimuli elicit a more positive-going wave (see, for example, Rugg, 1996), would imply larger late positivities following R-words in the recognition test, compared to both F-words and new words. It is then possible that the difference amplitude reflecting the signal detection indices, i.e. R-F and R-new, would increase after nicotine administration.

\section{METHOD}

\section{Subjects}

Eighteen male users of oral snuff (mean age 27.4, S.D. 4.0 years) were tested. All were users for at least 2 years (mean 10.4, S.D. 5.0 years). Average daily consumption of oral snuff was $32 \cdot 8$, S.D.
$18.4 \mathrm{~g} /$ day. Data from three of these were excluded due to admitted non-compliance with abstinence in one case, and excessive reaction to blood sampling in two cases. No other nicotine users reported any discomfort by the blood sampling. Seventeen male non-users of nicotine (mean age 24.9, S.D. 3.8 years) were tested in a similar manner. They did not receive nicotine and for practical reasons did not undergo blood sampling, as the main point of the control group was to provide a reference in terms of performance and ERPs in this type of task. Two control subjects were excluded due to technical fallacies.

\section{Procedure}

Subjects came to the laboratory for two sessions, separated by a week. Experiments were run at 8.00 a.m. or 10.00 a.m., and both sessions were run at the same hour. Subjects had been instructed to refrain from nicotine, alcohol, or caffeine for $12 \mathrm{~h}$. In one of the sessions, nicotine users applied oral snuff of their own preferred brand for $20 \mathrm{~min}$, after which the study test was run (see below). Nicotine use was balanced over sessions. Subjects were placed in a comfortable armchair. Subjects were instructed about the purposes of the experiment, and gave their written informed consent.

\section{Directed forgetting task}

The experiment was run using PsyScope 1.0.2 (Cohen et al., 1993). The subjects read five consecutive lists of 40 nouns each, with a short subjectterminated pause between each list. There were four counter-balanced sets of five lists. The nouns were selected from a pool of common nouns, sampling categories such as animals, vehicles, tools, etc. Words were randomly allocated to lists and categories. Words were shown in blue or red typeface, with instructions that blue words should be remembered (R-words) and red forgotten (F-words). Every list started and ended with two $\mathrm{R}$-coded buffer words that were not included in the recognition test. Every list comprised 15 words of either the R- or F-class, later included in the recognition test, along with three flower names of each colour. The flower names were included to ensure that subjects read all stimuli. The complete list of names of nine common flowers was shown to subjects beforehand. The subjects were instructed to read each word, and press a response button on a dedicated device (PsyScope ButtonBox) as soon 
as they encountered a flower name. Words were shown for $2000 \mathrm{~ms}$, and the inter-trial interval was $800 \mathrm{~ms}$. When the study task was completed, the subjects performed a distracter task (a choice reaction time task, data not reported), lasting approximately $7 \mathrm{~min}$.

Immediately following the distracter task, a recognition test was run, where all of the R- and F-words were presented (buffer words and flower names were excluded), together with 75 new words, also selected from the initial pool of nouns. All words were shown in black typeface. The subjects were to respond to R-words by pressing a designated response button, and to F-words and new words by pressing another button. Words were shown for $2000 \mathrm{~ms}$, with a response window of the same duration and an $800 \mathrm{~ms}$ inter-trial interval.

\section{Data recording}

Continuous EEG was recorded using a NeuroScan system. EEG was sampled at $250 \mathrm{~Hz}$ from the F3, $\mathrm{Fz}, \mathrm{F} 4, \mathrm{C} 3, \mathrm{Cz}, \mathrm{C} 4, \mathrm{P} 3, \mathrm{Pz}, \mathrm{P} 4$, and $\mathrm{Oz}$ derivations, with earlobes as reference. Oculo-motor artifacts were monitored using electrodes placed below the right eye, and at the outer left canthus, and were corrected off-line using NeuroScan software. EEG was converted into epochs starting $160 \mathrm{~ms}$ before stimulus onset and ending $1000 \mathrm{~ms}$ after onset. The pre-stimulus segment was used to correct the base-line of each epoch. Data was digitally band-pass filtered at $0 \cdot 3$ and $20 \mathrm{~Hz}$ with a $24 \mathrm{~dB}$ roll-off. Epochs were excluded if EEG amplitudes exceeded $\pm 100 \mu \mathrm{V}$ after correction for oculomotor artifacts.

\section{Data analysis}

In the encoding task, the average amplitude in the $500-750 \mathrm{~ms}$ interval, corresponding to the late positive component, was calculated at the $\mathrm{Cz}$ and $\mathrm{Pz}$ leads. For the recognition data, average amplitudes in the $350-550 \mathrm{~ms}$ interval, corresponding to the N400-like negativity, and the 550-850 interval, corresponding to the late positive component, were calculated for the $\mathrm{Fz}, \mathrm{Cz}$, and $\mathrm{Pz}$ electrodes. Mean reaction times were calculated for correct responses, and the signal detection index $\mathrm{d}^{\prime}$ was formed including $\mathrm{R}$ - and $\mathrm{F}$-words, $\mathrm{d}_{\text {old }}$, and for the R-words and new words, $\mathrm{d}_{\text {new }}$. Non-responses (mean 6\%, S.D. 6\%) were excluded from the calculation of the $\mathrm{d}^{\prime}$ indices. ERP difference measures corresponding to the $\mathrm{d}^{\prime}{ }_{\text {old }}, \mathrm{R}-\mathrm{F}$, and $\mathrm{d}_{\text {old }}, \mathrm{R}$-new, were formed.

\section{Nicotine analysis}

Blood samples were drawn from an antecubital vein before the start of the encoding task, and after the recognition task. Blood samples were immediately put on ice, and stored at $-18^{\circ} \mathrm{C}$ until analysis. Determination of nicotine was performed by capillary gas chromatography after a single-step liquid-liquid extraction of the plasma sample.

\section{Statistical analysis}

To counterbalance order effects, nicotine users were randomly assigned to receive nicotine in their first or second testing session. To achieve the same counterbalancing in the control group, each control subject was yoked in a pair with a nicotine subject, and his first and second session were assigned to a pseudo-nicotine and a pseudoabstinence condition, in parallel with his counterpart. Separate analyses are reported for the groups. Signal detection measures are analysed by a two session repeated measures ANOVA. Reaction time was analyzed by a 2 sessions $\times 3$ word classes ANOVA. A similar ANOVA, adding electrodes as a further within subjects factor, was used in the ERP analyses. Greenhouse-Geisser correction was applied when necessary.

\section{RESULTS}

\section{Nicotine levels}

The mean nicotine concentration in the abstinence pre-test samples was $3.36 \mathrm{ng} / \mathrm{ml}$ (S.D. 1.19), and in the post-test samples $2.93 \mathrm{ng} / \mathrm{ml}$ (S.D. 1.00). In the nicotine session, pre-test samples contained $11.06 \mathrm{ng} / \mathrm{ml} \mathrm{(S.D.} \mathrm{2.92),} \mathrm{and} \mathrm{post-test} \mathrm{samples}$ $14.95 \mathrm{ng} / \mathrm{ml}$ (S.D. 5.54).

\section{Encoding task}

Performance. The identification of catch trial words was quite high (Table 1), and unaffected by nicotine administration $[F(1,14)=1 \cdot 2, p=0 \cdot 30]$, and similar for R- and F-coded words $[F(1,14)<1$, n.s.]. There was no interaction between nicotine administration and stimulus class $[F(1,14)<1$, n.s.]. All comparisons in the control group were non-significant [all $F(1,14)<1$, n.s.]. 
Table 1. Encoding control test

\begin{tabular}{lrrrrr}
\hline Hit rate $(\%)$ & \multicolumn{2}{c}{ Abstinence } & & \multicolumn{2}{c}{ Nicotine } \\
\cline { 2 - 3 } \cline { 5 - 6 } & M & SD & & M & SD \\
\hline$R$-code & & & & \\
$\quad$ Nicotine $(n=15)$ & $90 \cdot 7$ & $16 \cdot 1$ & & $94 \cdot 7$ & $12 \cdot 6$ \\
Control $(n=15)$ & $96 \cdot 9$ & $4 \cdot 3$ & & $97 \cdot 8$ & $4 \cdot 1$ \\
$F$-code & & & & \\
$\quad$ Nicotine $(n=15)$ & $92 \cdot 4$ & $11 \cdot 5$ & & $92 \cdot 4$ & $18 \cdot 7$ \\
Control $(n=15)$ & $98 \cdot 2$ & $4 \cdot 7$ & & $98 \cdot 2$ & $3 \cdot 1$ \\
\hline
\end{tabular}

Event-related potentials. Average amplitudes for the late positive component can be found in Table 2.

The administration of nicotine had no effect on the amplitude of the late positive component $[F(1,14)<1$, n.s.], nor was there any significant
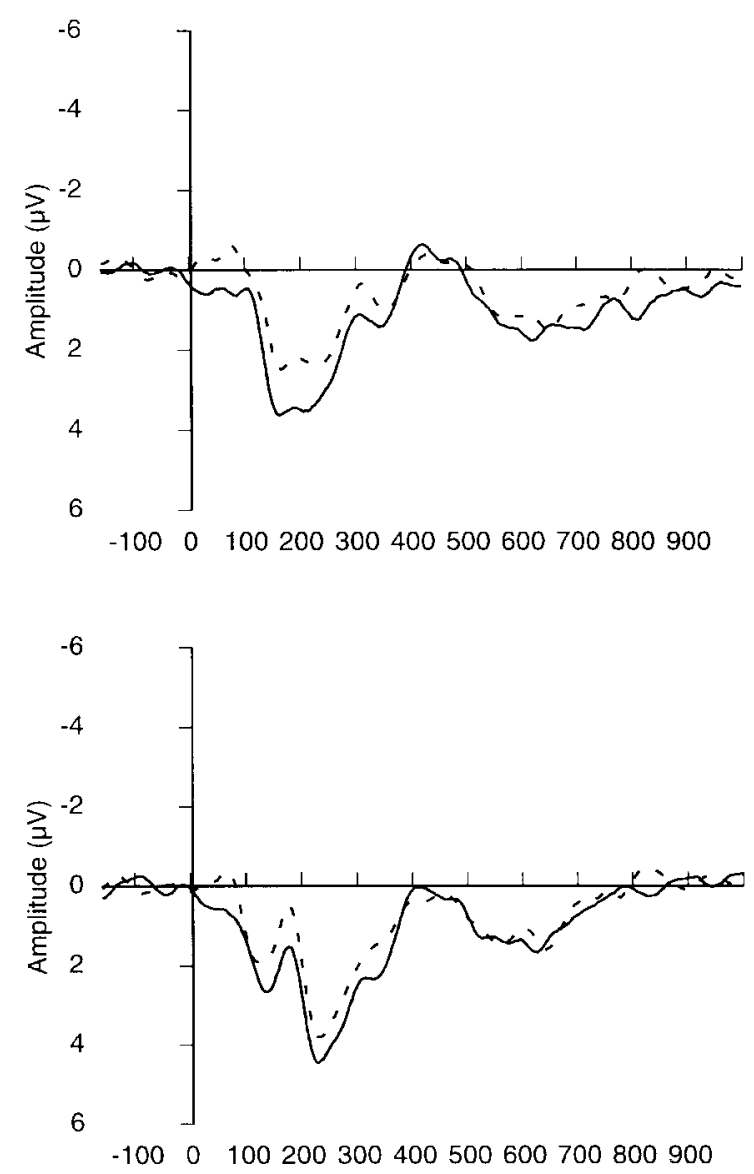

Table 2. Average amplitude in $\mu \mathrm{V}$ of the late positive component in the encoding task, collapsed over electrodes

\begin{tabular}{llllll}
\hline & \multicolumn{2}{c}{ Abstinence } & & \multicolumn{2}{c}{ Nicotine } \\
\cline { 2 - 3 } \cline { 6 - 6 } & M & SD & & M & SD \\
\hline$R$-word & & & & \\
$\quad$ Nicotine group $(n=15)$ & 0.82 & 1.52 & & 0.58 & 2.06 \\
$\quad$ Control group $(n=15)$ & 1.46 & 1.45 & & 0.26 & 2.05 \\
$F$-word & & & & \\
$\quad$ Nicotine group $(n=15)$ & 1.10 & 1.44 & & 0.62 & 1.55 \\
$\quad$ Control group $(n=15)$ & 1.34 & 1.75 & & 1.02 & 1.79 \\
\hline
\end{tabular}

difference between R- and F-stimuli $[F(1,14)<1$, n.s.], or any interaction $[F(1,14)<1$, n.s.] (Figure 1).
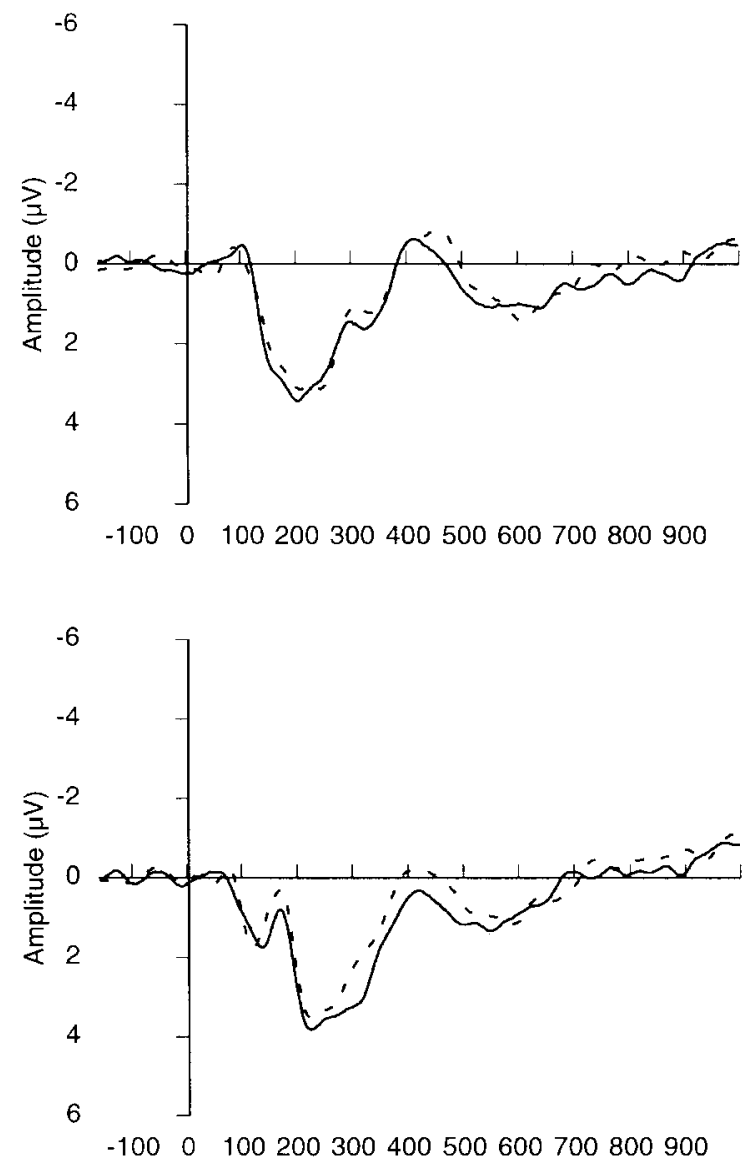

Figure 1. Grand averages from the encoding task for the nicotine group. Left panels depict abstinence, right panels the nicotine session, upper panels Cz, lower Pz. Solid lines $=\mathrm{R}$-words, dash $=$ F-words 

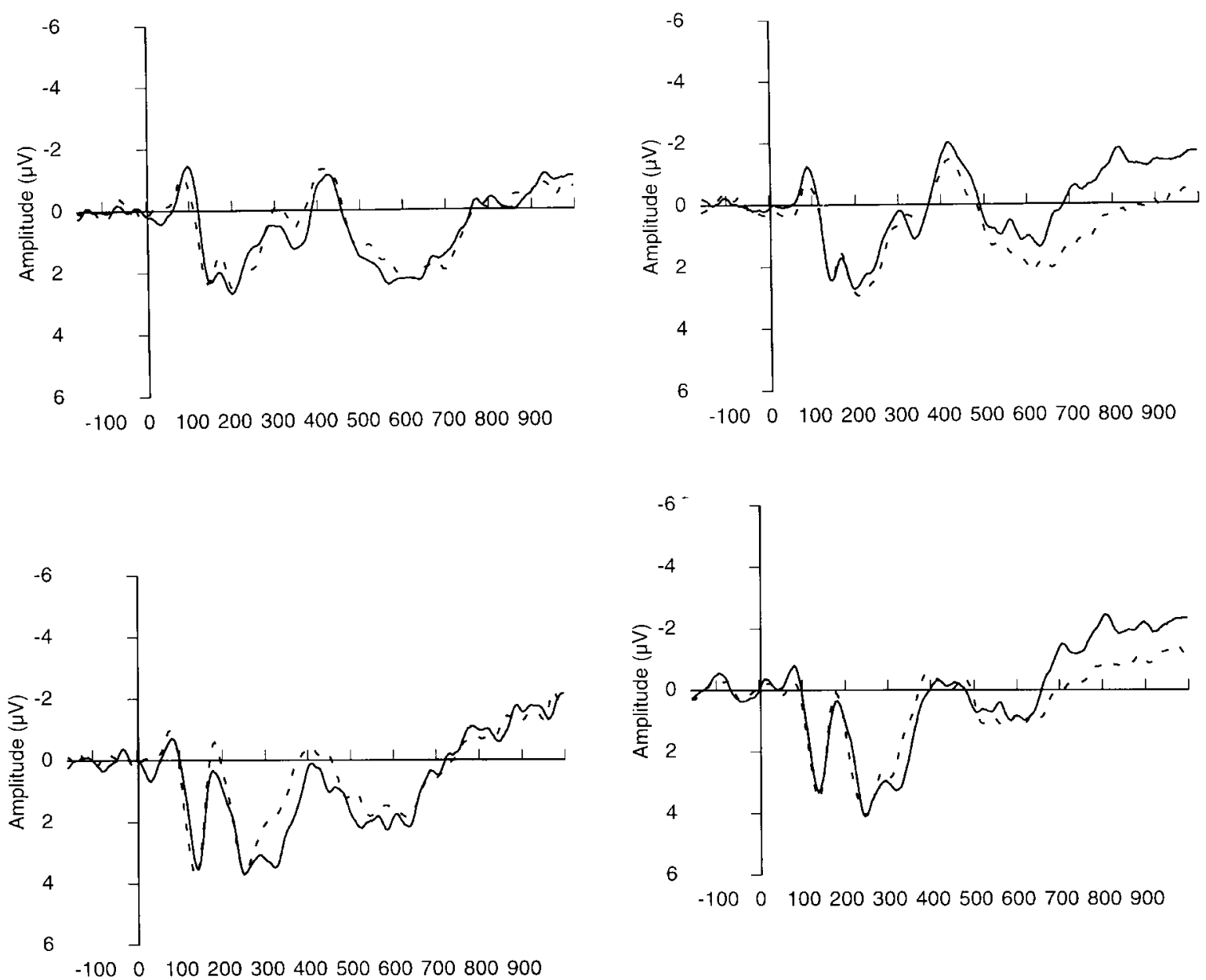

Figure 2. Grand averages from the encoding task for the control group. Left panels depict pseudo-abstinence session, right panels pseudo-nicotine session, upper panels $\mathrm{Cz}$, lower Pz. Solid lines $=\mathrm{R}$-words, dashed $=\mathrm{F}$-words

Controls were stable over sessions $[F(1,14)=$ $1 \cdot 7, p=0 \cdot 22]$, and there was no main effect of word classes $[F(1,14)=1 \cdot 5, p=0 \cdot 25]$. All other comparisons were non-significant $[F(1,14)<3 \cdot 8$, $p>0.07]$ (Figure 2).

\section{Recognition task}

Performance. Performance data can be found in Table 3. The task was difficult, with low identification of R-words, especially. Nicotine administration did not affect $\mathrm{d}^{\prime}{ }_{\text {old }}[F(1,14)=2 \cdot 3, p=$ $0 \cdot 15]$, but $\mathrm{d}_{\text {new }}$ was significantly higher after nicotine administration $[F(1,14)=12.9, \quad p=$ 0.003], indicating better recognition. Both measures were unaffected in the control group $[F(1,14)<1$, n.s.].
In the nicotine group, reaction time decreased significantly after nicotine administration $[F(1,14)=6 \cdot 1, p=0.03]$ (Table 4). There was no difference between word classes, nor any interaction $[F(2,28)<1.8, p>0.19$ in both cases].

Controls were stable over sessions $[F(1,14)=$ $1.4, p=0 \cdot 26]$, and there was no word class difference, nor any interaction effect $[F(2,28)<3 \cdot 1$, $p>0 \cdot 10]$.

Event-related potentials. Average amplitudes for the late negativity and the late positivity can be found in Table 5. Grand averages for the midline electrodes are shown in Figures 3 (nicotine group) and 4 (controls).

Late negativity. The administration of nicotine had no effect on the amplitude of the late negativity 
Table 3. Recognition test performance

\begin{tabular}{|c|c|c|c|c|}
\hline & Abstinence & Nicotine & $t(14)$ & $p$ \\
\hline \multicolumn{5}{|c|}{ Hit rate $R$-word (\%) } \\
\hline Nicotine & $46 \cdot 4$ & $53 \cdot 2$ & $2 \cdot 3$ & $0 \cdot 04$ \\
\hline Control & $43 \cdot 8$ & $46 \cdot \overline{5}$ & 0.52 & n.s. \\
\hline \multicolumn{5}{|c|}{ False alarms F-word (\%) } \\
\hline Nicotine & $32 \cdot 1$ & $31 \cdot 5$ & $0 \cdot 14$ & n.s. \\
\hline Control & $25 \cdot 5$ & $25 \cdot 3$ & $0 \cdot 06$ & n.s. \\
\hline \multicolumn{5}{|c|}{ False alarms new word (\%) } \\
\hline Nicotine & $20 \cdot 7$ & $15 \cdot 0$ & $2 \cdot 85$ & $0 \cdot 01$ \\
\hline Control & $12 \cdot 3$ & $11 \cdot 5$ & $0 \cdot 19$ & n.s. \\
\hline \multicolumn{5}{|l|}{$d^{\prime}{ }_{\text {old }}$} \\
\hline Nicotine & 0.42 & $0 \cdot 61$ & $1 \cdot 5$ & $0 \cdot 15$ \\
\hline Control & $0 \cdot 54$ & $0 \cdot 69$ & $0 \cdot 64$ & n.s. \\
\hline \multicolumn{5}{|l|}{$d^{\prime}{ }_{\text {new }}$} \\
\hline Nicotine & $0 \cdot 86$ & $1 \cdot 21$ & $3 \cdot 6$ & 0.003 \\
\hline Control & $1 \cdot 23$ & $1 \cdot 36$ & $0 \cdot 45$ & n.s. \\
\hline
\end{tabular}

Table 4. Reaction time in the recognition test

\begin{tabular}{lccccc}
\hline & \multicolumn{2}{c}{ Abstinence } & & \multicolumn{2}{c}{ Nicotine } \\
\cline { 2 - 3 } \cline { 5 - 6 } & $\mathrm{M}$ & $\mathrm{SD}$ & & $\mathrm{M}$ & $\mathrm{SD}$ \\
\hline R-word & & & & \\
$\quad$ Nicotine $(n=15)$ & 1118 & 157 & & 1044 & 132 \\
$\quad$ Control $(n=15)$ & 1107 & 126 & & 1094 & 161 \\
F-word & & & & \\
$\quad$ Nicotine $(n=15)$ & 1146 & 178 & & 1081 & 174 \\
Control $(n=15)$ & 1129 & 166 & & 1091 & 140 \\
New word & & & & \\
$\quad$ Nicotine $(n=15)$ & 1130 & 183 & & 1001 & 178 \\
Control $(n=15)$ & 1056 & 171 & & 1038 & 167 \\
\hline
\end{tabular}

$[F(1,14)<1$, n.s.], and there was no significant difference between word classes $[F(1,14)=1 \cdot 1$, $p=0 \cdot 34]$. The interaction between word class and electrode was significant $[F(4,56)=3 \cdot 3, p=0 \cdot 04]$. However, when re-scaled (McCarthy and Wood, 1985) to compensate for problems with nonadditivity, this was attenuated $[F(4,56)<1$, n.s.]. All other terms were non-significant $(p>0.19)$. Both difference measures, analogous to $\mathrm{d}^{\prime}{ }_{\text {old }}$ and $\mathrm{d}_{\text {new }}$, were unaffected by nicotine administration $[F(1,14)<1$, n.s. $]$

Controls were stable over sessions $[F(1,14)<1$, n.s.], and there was no main effect of word class $[F(1,14)<1$, n.s.], and no interaction between session and word class $[F(1,14)<1$, n.s.]. The amplitude decreased from anterior to posterior leads $[F(2,28)=5.9, \quad p=0.01] . \quad$ All other
Table 5. Event-related potential parameters for the recognition task, collapsed over electrodes

\begin{tabular}{|c|c|c|c|c|}
\hline & \multicolumn{2}{|c|}{ Abstinence } & \multicolumn{2}{|c|}{ Nicotine } \\
\hline & M & $\mathrm{SD}$ & M & $\mathrm{SD}$ \\
\hline \multicolumn{5}{|l|}{ Late negativity amp. $(\mu \mathrm{V})$} \\
\hline \multicolumn{5}{|c|}{$R$-word } \\
\hline Nicotine $(n=15)$ & $-0 \cdot 11$ & $2 \cdot 18$ & $-0 \cdot 69$ & $2 \cdot 84$ \\
\hline Controls $(n=15)$ & $-0 \cdot 17$ & $2 \cdot 57$ & $-0 \cdot 05$ & $2 \cdot 01$ \\
\hline \multicolumn{5}{|l|}{ F-word } \\
\hline Nicotine $(n=15)$ & $0 \cdot 33$ & $2 \cdot 13$ & $-0 \cdot 08$ & $1 \cdot 63$ \\
\hline Controls $(n=15)$ & $0 \cdot 16$ & 1.82 & $0 \cdot 22$ & 1.96 \\
\hline \multicolumn{5}{|l|}{ New word } \\
\hline Nicotine $(n=15)$ & $-0 \cdot 05$ & 1.67 & $0 \cdot 16$ & $1 \cdot 84$ \\
\hline Controls $(n=15)$ & $-0 \cdot 40$ & $2 \cdot 28$ & $0 \cdot 12$ & $1 \cdot 72$ \\
\hline \multicolumn{5}{|l|}{ Late positivity amp. $(\mu \mathrm{V})$} \\
\hline \multicolumn{5}{|l|}{$R$-word } \\
\hline Nicotine $(n=15)$ & $0 \cdot 37$ & $2 \cdot 01$ & $-0 \cdot 10$ & $2 \cdot 95$ \\
\hline Controls $(n=15)$ & $1 \cdot 15$ & $2 \cdot 31$ & $1 \cdot 56$ & $2 \cdot 67$ \\
\hline \multicolumn{5}{|l|}{ F-word } \\
\hline Nicotine $(n=15)$ & $1 \cdot 04$ & 1.95 & $0 \cdot 77$ & $1 \cdot 57$ \\
\hline Controls $(n=15)$ & $1 \cdot 34$ & $2 \cdot 16$ & $1 \cdot 54$ & $2 \cdot 09$ \\
\hline \multicolumn{5}{|l|}{ New word } \\
\hline Nicotine $(n=15)$ & 1.40 & 1.42 & 1.62 & 1.86 \\
\hline Controls $(n=15)$ & 1.66 & $2 \cdot 33$ & $2 \cdot 16$ & 1.67 \\
\hline
\end{tabular}

comparisons were non-significant $(p>0 \cdot 18)$. Difference measures were stable over sessions $[F(1,14)<1$, n.s.].

Late positivity. The administration of nicotine had no effect on the amplitude of the late positivity $[F(1,14)<1$, n.s.]. There was a difference between word classes $[F(2,28)=6 \cdot 6, p=0 \cdot 01]$, as new words elicited larger amplitudes than old $[F(1,14)=9 \cdot 1, p=0 \cdot 01]$. The interaction between word class and session was not significant $[F(2,28)<1$, n.s.]. There was a difference between electrodes $[F(1,14)=14.4, p=0 \cdot 01]$, with smaller amplitudes at Fz. All other terms were nonsignificant $(p>0 \cdot 12)$. Difference measures were stable over sessions $(F(1,14)<1$, n.s.].

Controls were stable over sessions $[F(1,14)=1 \cdot 6, p=0 \cdot 23]$, and there was no main effect of word class $[F(1,14)=1 \cdot 1, p=0 \cdot 33]$, and no interaction between session and word class $[F(1,14)<1$, n.s.]. The amplitude was highest at $\mathrm{Cz}$ $[F(2,28)=8 \cdot 8, p=0 \cdot 01]$. All other comparisons were non-significant $(p>0 \cdot 15)$. Difference measures were stable over sessions $[F(1,14)<1$, n.s.]. 

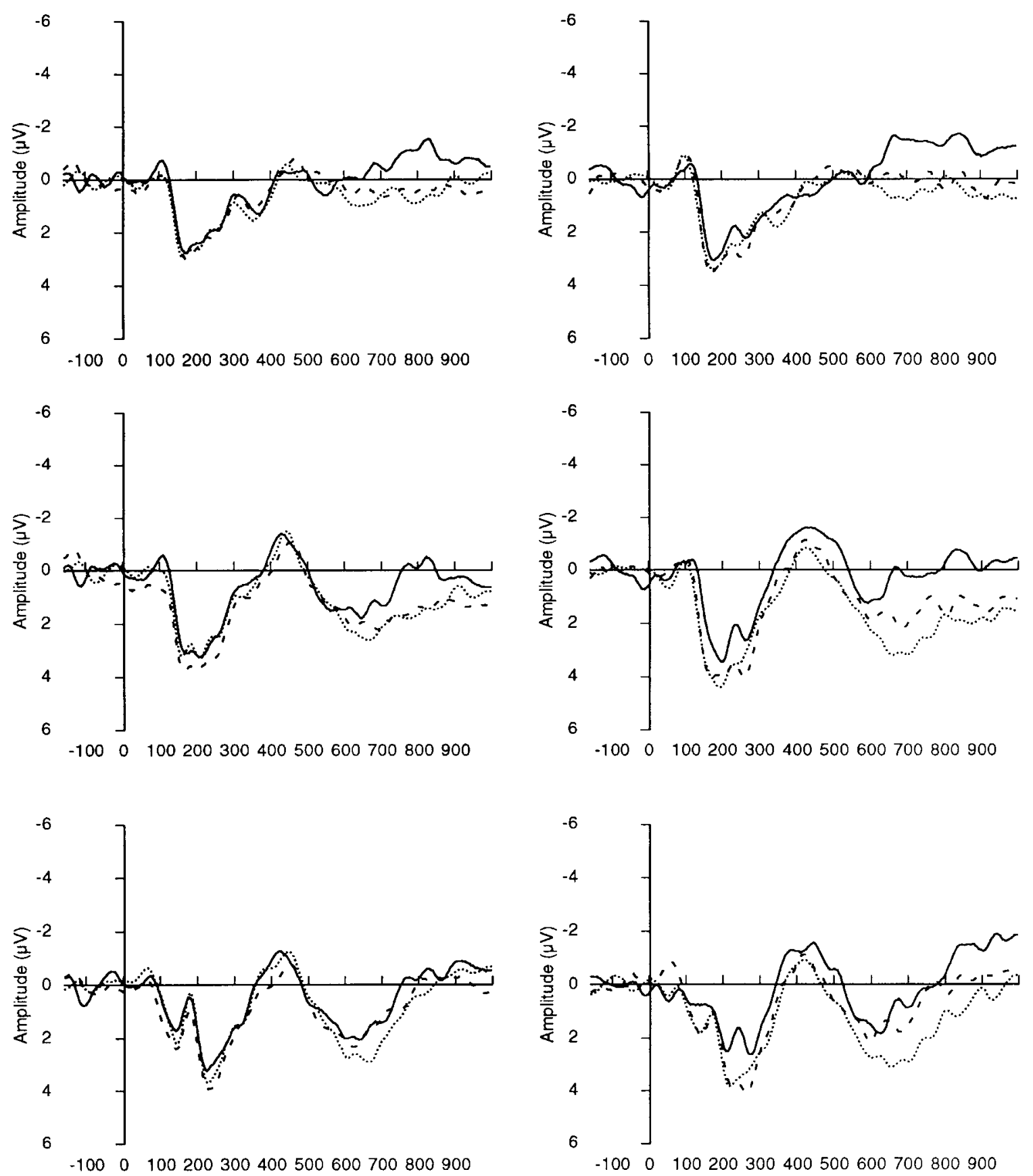

Figure 3. Grand averages formed for correct responses in the recognition task for the nicotine group. Left panels depict abstinence, right panels the nicotine session, upper panel Fz, mid Cz, lower Pz. Solid lines $=\mathrm{R}$-words, dashed $=\mathrm{F}$-words, dotted lines $=$ new words 

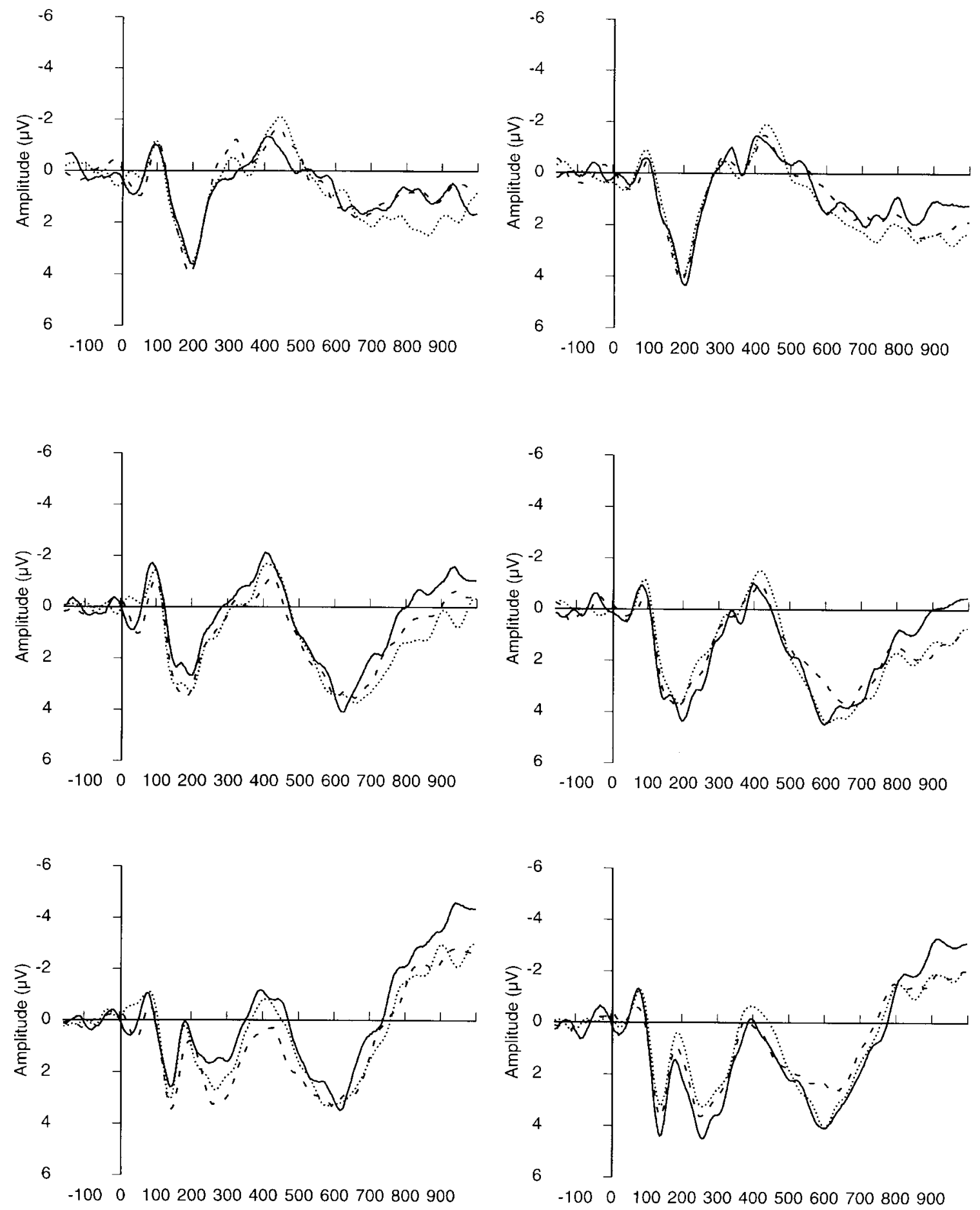

Figure 4. Grand averages formed for correct responses in the recognition task for the control group. Left panels depict pseudoabstinence session, right panels the pseudo-nicotine session, upper panel $\mathrm{Fz}$, mid $\mathrm{Cz}$, lower Pz. Solid lines $=\mathrm{R}$-words, dashed $=$ F-words, dotted lines $=$ new words 


\section{DISCUSSION}

The administration of oral snuff improved the discrimination between R-words and new words in the recognition test. The discrimination inherent in the directed forgetting task was not reliably affected. Assuming that a more effective allocation of resources in the study phase would be reflected in an increased $\mathrm{d}^{\prime}{ }_{\text {old }}$, we found no positive support for improved strategic use of cognitive resources. Furthermore, performance after nicotine administration was comparable to that of the control group, indicating that there was no supra-normal improvement of performance.

Event-related potentials in the encoding phase showed no pertinent effects. It is likely that the encoding instruction was insufficient to yield any separation between stimulus classes. Encoding details such as the Dm are also affected by the subject's strategy, e.g. opting for rote rehearsal versus some facilitating organisation of the material (Donchin and Fabiani, 1991). This was not explicitly controlled in the present experiment.

Response time decreased generally after nicotine administration. This is a frequent, if not constant, finding in simple psychomotor task (Sherwood, 1993; Heishman et al., 1994). The present study would seem to have more in common with previous studies of memory scanning, which have frequently employed the Sternberg task. Decreased memory scanning times have been demonstrated (West and Hack, 1991; Sherwood et al., 1991), although not uniformly (Spilich et al., 1992; Foulds et al., 1996).

The task used was difficult and performance fairly low. Wilding and Rugg (1997) reported higher hit-rate than found in the present study, but roughly comparable performance for F-words and new words. They noted that a double encoding classification was necessary to reach a comparatively high discrimination between $\mathrm{R}$ - and F-words, whereas a single encoding classification (flower or not?) was used in the present task. The failure to find any pertinent amplitude differences between R-and F-words is probably due to the low discrimination between these categories, as Wilding and Rugg point out in connection with their exclusion task. Furthermore, directed forgetting might give clearer results when used with a recall test, rather than the recognition test chosen in the present study (Golding et al., 1994), although it is quite possible to use the technique with recognition tests.
We expected that previously shown words should elicit larger late positivities in the recognition test, in line with previous findings (Rugg, 1996). In fact, the opposite was found in the nicotine group, as new words elicited the larger positivities, while there was no difference in the control group. In view of the larger proportion of correct responses for new words, it is possible that these have stood out, causing a 'target' effect analogous to the odd-ball P300 (Picton, 1992), which might speculatively have attenuated repetition effects.

When a difficult task such as ours is used, there is always a risk that motivation deficiencies or floor effects affect results. This would mean an increased risk of Type II errors, as results would not reflect subtle changes in performance. Whereas an optimized task certainly should be used in further studies, one must note that performance improvements were found in the nicotine group, thus implicating that our task has been appropriate, though not ideal, to our purpose.

Our design confounds actual nicotine effects with the relief of abstinence. This makes the interpretation of the increased $\mathrm{d}^{\prime}{ }_{\text {new }}$ somewhat unclear. However, we tentatively suggest that a relief of abstinence is perhaps the major factor, as performance in the nicotine group after nicotine administration was comparable to the control group.

The possibility of strategic aspects of nicotine use would demand a more systematic mapping of nicotine level, task load and situation to get a satisfactory answer (Perkins, 1995), however, in the present study, the results were not indicative of greater strategic control. Generally, our results instead seem to point towards an alleviation of abstinence, 'normalizing' nicotine users' performance in the relatively easy part of the recognition task, expressed as $\mathrm{d}^{\prime}{ }_{\text {new }}$. The results are in general agreement with earlier findings in our laboratory of nicotine effects on arousal and psycho-motor speed, but not on selective attention (Lindgren et al., 1996, 1998).

\section{ACKNOWLEDGEMENTS}

This research was supported by the Swedish Tobacco Company (grants no.9320 and 9412), and the Medical Research Council (grant no. B9514J-00084-31B). Fredrik Kuylenstierna, PharmaciaUpjohn Consumer Health Care, generously helped with nicotine analyses. 


\section{REFERENCES}

Cohen, J., MacWhinney, B., Flatt, M. and Provost, J. (1993). PsyScope: an interactive graphic system for designing and controlling experiments in the psychology laboratory using Macintosh computers. Behavior Research Methods, Instruments, and Computers, 25, 257-271.

Curran, T. and Hintzman, D. L. (1997). Consequences and causes of correlations in process dissociation. Journal of Experimental Psychology: Learning, Memory and Cognition, 23, 496-504.

Donchin, E. and Fabiani, M. (1991). The use of eventrelated potentials in the study of memory: is P300 a measure of event distinctiveness? In Handbook of Cognitive Psychophysiology: Central and Autonomic System Approaches, J. R. Jennings and M. G. H. Coles (Eds.), John Wiley, Chichester, pp. 471-498.

Foulds, J., Stapleton, J., Swettenham, J., Bell, N., McSorley, K. and Russell, M. A. H. (1996). Cognitive performance effects on subcutaneous nicotine in smokers and never-smokers. Psychopharmacology, 127, 31-38.

Golding, J. M., Long, D. L. and MacLeod, C. M. (1994). You can't always forget what you want: directed forgetting of related words. Journal of Memory and Language, 33, 439-510.

Heishman, S. J., Taylor, R. C. and Henningfield, J. E. (1994). Nicotine and smoking: a review of effects on human performance. Experimental and Clinical Psychopharmacology, 2, 345-395.

Hillyard, S. A. and Münte, T. F. (1984). Selective attention to colour and locational cues: an analysis with event-related brain potentials. Perception and Psychophysics, 36, 185-198.

Houston, J. P., Schneider, N. G. and Jarvik, M. E. (1978). Effects of smoking on free recall and organization. American Journal of Psychiatry, 135, 220-222.

Jacoby, L. L. (1991). A process dissociation framework: separating automatic from intentional uses of memory. Journal of Memory and Language, 30, 513-541.

Jacoby, L. L., Toth, J. P. and Yonelinas, A. P. (1993). Separating conscious and unconscious influences on memory: measuring recollection. Journal of Experimental Psychology: General, 122, 139-154.

Jacoby, L. L., Begg, I. M. and Toth, J. P. (1997). In defense of functional independence: violations of assumptions underlying the process-dissociation procedure? Journal of Experimental Psychology: Learning, Memory, and Cognition, 23, 484-495.

Johnson, H. M. (1994). Processes of successful intentional forgetting. Psychological Bulletin, 166, 274-292.

Karis, D., Fabiani, M. and Donchin, E. (1984). P300 and memory: individual differences in the von Restorff effect. Cognitive Psychology, 16, 177-186.

Levin, E. D. (1992). Nicotinic systems and cognitive function. Psychopharmacology, 108, 417-431.
Levin, E. D., Kim, P. and Meray, R. (1996). Chronic nicotine working and reference memory effects in the 16-arm radial maze: interactions with D1 agonists and antagonist drugs. Psychopharmacology, 127, 25-30.

Lindgren, M., Stenberg, G. and Rosén, I. (1996). Effects of nicotine in visual attention tasks. Human Psychopharmacology, 11, 47-51.

Lindgren, M., Stenberg, G. and Rosén, I. (1998). Effects of nicotine in a bimodal attention task. Neuropsychobiology, 38, 42-49.

McCarthy, G. and Wood, C. C. (1985). Scalp distributions of event-related potentials: an ambiguity associated with analysis of variance models. Electroencephalography and Clinical Neurophysiology, 62, 203-208.

Mulligan, N. W. and Hirshman, E. (1997). Measuring the bases of recognition memory: an investigation of the process-dissociation framework. Journal of Experimental Psychology: Learning, Memory, and Cognition, 23, 280-304.

Paller, K. A. (1990). Recall and stem-completion have different electrophysiological correlates and are modified differentially by directed forgetting. Journal of Experimental Psychology: Learning, Memory and Cognition, 16, 1021-1032.

Parrott, A. C. and Winder, G. (1989). Nicotine chewing gum ( $2 \mathrm{mg}, 4 \mathrm{mg}$ ) and cigarette smoking: comparative effects on upon vigilance and heart rate. Psychopharmacology, 97, 257-261.

Peeke, S. C. and Peeke, H. V. S. (1984). Attention, memory, and cigarette smoking. Psychopharmacology, 84, 205-216.

Perkins, K. A. (1995). Individual variability in responses to nicotine. Behavioral Genetics, 25, 119-132.

Picton, T. (1992). The P300 wave of the human eventrelated potential. Journal of Clinical Neurophysiology, 9, 456-479.

Rugg, M. D. (1996). ERP studies of memory. In Electrophysiology of Mind, M. D. Rugg and M. G. H. Coles (Eds.), Oxford Psychology Series, 25, Oxford University Press, Oxford, pp. 132-170.

Rusted, J., Graupner, L. and Warburton, D. (1995). Effects of post-trial administration of nicotine on human memory: evaluating the conditions for improving memory. Psychopharmacology, 119, 405-413.

Sherwood, N. (1993). Effects of nicotine on human psychomotor performance. Human Psychopharmacology, 8, 155-184.

Sherwood, N., Kerr, J. S. and Hindmarch, I. (1991). Effects of nicotine gum on short-term memory. In Effects of Nicotine on Biological Systems, F. Adlkofer and K. Thurau (Eds.), Advances in pharmacological sciences. Birkhäuser, Basel, pp. 531-535.

Spilich, G. J., June, L. and Renner, J. (1992). Cigarette smoking and cognitive performance. British Journal of Addiction, 87, 1313-1326. 
Warburton, D. M. (1992). Nicotine as a cognitive enhancer. Progress in Neuro-Psychopharmacology and Biological Psychiatry, 16, 181-191.

Warburton, D. M., Rusted, J. M. and Fowler, J. (1992a). A comparison of the attentional and consolidation hypotheses for the facilitation of memory by nicotine. Psychopharmacology, 108, 443-447.

Warburton, D. M., Rusted, J. M. and Müller, C. (1992b). Patterns of facilitation of memory by nicotine. Behavioural Pharmacology, 3, 373-378.
West, R. and Hack, S. (1991). Effects of cigarettes on memory search and subjective ratings. Pharmacology Biochemistry \& Behavior, 38, 281-286.

Wijers, A. A., Mulder, G., Okita, T., Mulder, L. J. M. and Scheffers, M. K. (1989). Attention to colour: an ERP analysis of selective attention, controlled search and motor activation. Psychophysiology, 26, 89-109.

Wilding, E. L. and Rugg, M. D. (1997). Event-related potentials and the recognition memory exclusion task. Neuropsychologia, 35, 119-128. 